\title{
Framework for Drop Trailer Method (DTM) of Haulage Industry in Malaysia
}

\section{Mazlan Md Zahid ${ }^{1}$, Mustakim Melan ${ }^{2}$, Rohafiz Sabar ${ }^{3}$, Pichit Prapinit ${ }^{4}$, Patchateeya Booyarit ${ }^{5}$, Anucha Wilaikaew ${ }^{6}$, Pairoj Chatchawan ${ }^{7}$, Mohamad Ghozali Hassan ${ }^{8}$}

${ }^{1}$ Faculty of Industry Logistics, Universiti Kuala Lumpur, 81750 Masai, Johor, Malaysia

${ }^{2,3,8}$ Disaster Management Institute (DMI), School of Technology Management and Logistics,

College of Business, Universiti Utara Malaysia, 06010 Sintok, Kedah

${ }_{4,5,6,7}$ Loei Rajabhat University(LRU), Loei - Chiang Kan, Loei 42000, Thailand

mazlanmz@unikl.edu.my1, mustakim@uum.edu.my²,rohafiz@uum.edu.my ${ }^{3}$,pichitprapinit@gmail.com ${ }^{4}$, logistic.border.lru@gmail.com ${ }^{4}$,ghozali@uum.edu.my ${ }^{8}$

Article History: Received: 10 November 2020; Revised: 12 January 2021; Accepted: 27January 2021;

Published online: 05April 2021 Abstract: This study focuses on trailers' utilization turn-around and fleets deployment of haulage industry in Malaysia. The
study proposes a framework for Drop Trailer Method (DTM) which is suitable at present competitive business and suggest
for specific mechanism in maximizing of fleets capacity. The ratio of 1:7 for prime movers and trailers was suggested which
suitable for movement planning and better scheduling. It reflects with a complete system that requires in monitoring on the
deployment of the machineries especially on the timing of DTM. Haulage industry involved with huge capital investment
which therefore an appropriate planning and optimizing the trailers are significant. This is an exploratory study where the
interviews were carried out among the 12 nominated haulage companies and its customers and at the end a qualitative
research was adopted. Through the implementation on the proposed framework of DTM, the operational in haulage industry
will be more effective and better impacts on trailers' performance. The results indicated that the effectiveness of DTM is
based on coordination and utilization of trailers. The DTM framework is suggested to be used in the measurement on the
performance of trailers' turn-around of haulage industry in future.

Keywords:drop trailer method, framework turn around, fleet capacity, trailer performance, turn around capacity, competitive business and impacts planning

\section{Introduction}

Haulage industry is a group of trucking businesses with the daily functions to transporting containers from place to another. It involves with local and long distance deliveries and the specific customers were in categories of manufacturing industry, factories, warehouses, container yards, forwarding agents, shipping lines for the purpose of import and exports containers. A little request for haulage container services from individual or group of peoples. The container haulage was very familiar since 80 s where most of the importer and exporters were using containers as their mode of movement with the availability of containerized vessels. Huge market forces especially for import and exports containers were invited growth in haulage industry. The movements through haulage containers are considered the safest, trust worthiness and reliable until present. Most of the haulage industry had operated the companies around the industrial areas, seaport, rail industry and also at the international borders which connected with nearest to other modes of transport as well (Omotayo and Melan, 2017)[22]. Since the most of the exporters and imports are using the containers as their mode, the numbers of fleets in haulage industry were recorded oversupply and faced the risks in their financial sustainability (Tengku Jamaluddin, 2003)[29]. The war pricing in haulage services was also recorded and consequently invites instability and sinking the level of customers' fulfilment (Maria Emilson\& Hanna Johansson, 2011)[16].

Refining performance through employing the asset is always a mutual method adopted by the hauliers to generate optimum revenue from the operations. The haulage business is a one of massive industry and demonstrates and expands in costs consistently. The number of prime movers in the company is less than the trailer with specific ratio to $1 / 7$ [21]. Which therefore appropriate actions are needed to be taken to improve loses in fleets' times especially in the trailers' turn-around. Through this exercises the haulage company may be survived in the market for the long run. In meeting this requirement, the effectiveness of drop trailer method (DTM) should be in place (Melan and Zahid, 2019)[18]. They also mentioned on the calculation should be made on the usage of trailers and detained by the customers in order to maximize the movements. Expected the scenario, it is validating that an investigation towards the existing practices in perceiving the drop trailer method (DTM) movement planning framework is necessary.

\section{Background}

\subsection{The Problem in Trailers Management}


A numeral of studies by VojkoPotocan, (2006), Parwani K \& Jagadeesh R, (2012), Bolstorff, P (2007) and Bowersox, D.J (2002) [30] have viewed into the approaches engaged to improve the drop trailer performance for the benefit of trucking companies, they only emphasized management of fleets that measured based on the prime movers but not for it trailers (Tengku Jamaludin,2003)[29] \& (Oyster Bay, NY: ABI Research, 2005)[23]. Meanwhile trailers are over and over again costly and implicate high cost in any haulage organizations there were also literature by Johnson, (2008)[13] reporting on this type of fleets should be entirely optimized however depending on the fleet performance. However, within the haulage operation, trailer which used to load the container and haul by the Prime Mover (PM) is always being sideline in term of it performance. Zailani and Zaly(2007)[31] revealed that majority of the Haulage operators are more interested to measure their performance through financial indicator although some of them claim did measure the equipment utilization particularly in term of availability. Omotayo and Melan (2017)[22] discussed on factors influencing the information and communication technology (ICT) of third party logistics are the most reliable function in the system which relate to the Fleet Management Systems (FMS) and trailers' management. This is also able to control the timing for the detained trailers and manage with other assignments. It also revealed on the approach of quantifying energy in terms of economic, environmental and supply risk factors which related to the idling trailers for the longer period of times which caused on the negative impacts to operators. Azizi, Hassan, Akanmu and Melan (2019)[1] discussed on the relationship between logistical support factors and effective contract management which between haulage operators and customers should be having a structured contract and mutual understanding prior commencing the business. Hence, it is crucial for trucking industry', to have plans on their drop trailer method for optimization comprehensively so as to extend the performance of its trailers. Therefore, with such inadequate studies being embarked on this investigation turn out to be a spinning in varying the insufficiency. Jalil, Prapinit, Melan and Mustaffa(2019)[11] revealed on an adoption of business intelligence, technological, individual and supply chain efficiency and also related the monitoring parts in order to maximize the fleets movement.

\subsection{Fleets Movement and Management Practices}

Hence, many operators were presented after 1991 in reaction to increase for healthier services and cater the upsurge requests. Meanwhile, the hauliers have been progress from five hauliers in 1999 to more than 220 operators at present in Malaysia. It had demonstrated in the growth of total fleet from 2,131 prime movers and 10,701 trailers in 1999 to 4,500 over prime movers and 24,000 over trailers nationwide (MHA, 2014)[15]. The ratios number of prime mover and trailer is 1;7[21]. Normally in this industry, whereby a container that needs to be loading or unloading is left mounted on its chassis at its starting point or ultimate destination. The trailer with container is left at the customers' places for several days waiting for loading and unloading and for the warehouse purposes. Miller (1990) [20] determined on customer service, using five type mechanisms such as request date, first acknowledgement, published interval, last acknowledgement, and last positive acknowledgement. This also related to ICT (Omatayo and Melan, 2017) [22] and FMS (Melan and Zahid, 2019) [8]. Each measure was associated with a shipping planning and timeline encompassing from pickup to drop-off. Mentzer and Konrad (1991)[19] registered a collection of efficiency and effectiveness performance measures in Five (5) categories: transportation, warehousing, inventory control, order processing, and logistics administration. Prapinit, Sabar, Melan (2019)[26] reffered on the demand for Logistics Management Studies which explain on the knowledge should be equipped by the personnel dealing with daily job in transport companies. The trailers availability for operation is acknowledged expressively affected by the movement of a drop-trailer method operation. This principally backed from great number of trailers while left at the users premises or at ports which unable to be utilized for the delivery. Azizi, Hassan, Akanmu and Melan(2019)[1] relates on the relationship between logistical support factors and effective contract management which refer to contract agreement with the customers for better understanding for monitoring the fleets.

Halizahari and Mustakim (2016)[12] revealed on the initiatives to prolong aging assets life cycle which the trailers (asset) are supposed to be maximized in the movement for profit maximization. The usage times of trailers will include the inspection and maintenance. Besides, other factor that affecting the turnaround time of the trailers is a distance of haulage. Since the shipper and consignee are situated over a broadly spread geographical area, the movement turnaround time and accessibility of both prime movers and trailers are constantly the challenges to the hauliers. Omotayo and Melan (2017)[22] discussed on the factors influencing the information and communication technology (ICT) of third party logistics which able to monitor the whole movements of the fleets with effective manner. This could be the purpose the industrial ratio for container haulage in Malaysia (prime mover to trailer) is typically considered to be at high site at 1: 5 to 7 versus other countries in Europe merely having a ratio 1:3. Moreover, only a limited of studies by Oyster Bay (2005)[23], Parwani K and Japadeesh R (2012)[24] lovelock, Peter MbuthiaGitahi, Dr Kennedy Ogollah, (2014)[25], Mauro Vivaldini, Silvio R I Pires (2012)[17], and Zaly, M. and Zaid, Z. (2007)[31], have examined the performance 
evaluation in haulage industry. In fact, the practice in the existent haulage industry requires trailers to be deployed in optimal level Christopher M, (2011)[7].

\subsection{Fleets Movement Management Framework in Haulage Industry.}

Fleets management framework refers the formulation of concept and movement planning, journey planning, movement delivery, movement monitoring and collections (Bowersox, Closs\& Cooper, 2002 [5]; David J. et al., 2016[8]; Forslund, 2007;[10] Azlan M et al., 2014[2]; Fabricio, 2004[9], Melan, 2017)[18]. The similar concept which the fleets movement planning is a process of managing fleets, commencing with the concept of fleets or resources movement planning until the container unit being collected or picked up and lift or un-lifting from its trailers. Since the number of trailers are huge, customers and location are scattered the hauliers had difficulties in monitoring the trailers.Halizahari and Mustakim (2016)[12] refers on aging assets life cycle which are suitable in monitoring the asset for long lasting used and in-order to maximize on the usages. Therefore, the hauliers had taken an action by establishing trailers detention monitoring program which can optimize the trailers utilization. In sustaining the viability, the container industry should be more focus on trailers management in order to increase the trailers turn around efficiently. Melan, Zahid, Sabar(2019)[18] relates on effectiveness on Drop Trailer Method (DTM) of Haulage Industry especially on the fleets management and its combination for monitoring purposes. With better trailers monitoring and performance dimension, the haulage companies will focus in optimizing the numbers of movement of the machines according to the needs as required by customers and reducing on the idling times and maintenance costs.

\section{Research Objectives}

This study is to investigate the applicability of drop trailer method management framework for Haulage Industry in Malaysia and Thailand. This is a preliminary and comprehensive investigation and objectives of this study are:

a. To investigate the formulation of movement planning on trailers in haulage industry

b. To examine the process of fleets management on drop trailer method for an optimal movement delivery.

c. To identify the movement monitoring and collection on trailers in Haulage Industry.

\section{Methodology}

The qualitative approach is chosen as the research design for this study. Additionally, the researcher had been in the direction of numerous participant proficiencies in understanding the phenomena. Therefore, the researcher depend much on the views speak out by the participants to study the scenario (Creswell, 2013)[6]. Facts were gathered as much as possible where the questions turned wider and further open-ended questioning had been applied for the participants to share their opinions. Accordingly, greatest opinions had been based on participants' experiences that involved historical norms. As such, this study implemented the Qualitative Research Approach in order to discover the details of applicability of drop trailer method management framework in Malaysia Haulage Industry. On the other hand, the qualitative approach is suitable for this study as it expresses greater depth in understanding issues. In exact, it refers to meanings, definitions, concepts, metaphors and descriptions of several elements (Berg, 2001)[4]. This approach allows exploration of a phenomenon by using wide foundations (Baxter \& Jack, 2008)[3]. The strength of this qualitative research is to bring complex textual descriptions, particularly on this topic which cannot be performed quantitatively. In this study, the interview method of qualitative research is used by researcher to collect data from selected 13 container haulage players that have significant presence in Malaysia located at Johor Bahru, Port Klang and Penang. Trans-border counterparts were selected with the several branches in Malaysia and the places for the survey located at border areas of Thailand such as Had Yai ,Danok, Songkhla, Padang Besar and Bukit KayuHitam. The areas of survey were conducted at the trailers' yards owned by the selected companies. In line of the confidentiality and requested from the respondents, the details of the respondents are unable to reveal instead being identified as Company 1 to company 13. The respondents are assuming the roles of operation manager, manager and senior executive from the selected companies.

\section{Findings and Discussion}

Fleets movement framework on DTM is vital to determine the trailers utilization to maximize the movement and deliveries. Having the right approach, haulage players are capable to ascertain the growth of the company and implement the movement according to the business requirement. Data collected from interviewees are able to penetrate the matters which contributed to the drop trailer movement (DTM) framework. This segment reflected the consequences from the interview in order to deliver response for research questions as mentioned. 


\subsection{Formulation of Concept and Movement Planning.}

The volume of container throughputs in Malaysian for the year recorded to 23,783,893 Teus (Malaysian Haulage Association, (2014)[15] where the containers units required the prime movers and trailers for the delivery to the end customers. The container haulage operation by road is a dedicated form of transport, which is designed to haul only containers. It consists of a prime mover and a trailer unit upon which a container is loaded. The traction unit can be attached to or detached from the trailer unit. The trailer unit is designed to haul the 20footer containers or a single 40-footer container. Essentially, container movement planning decisions are made within the operational planning contexts which are resources planning, delivery and monitoring of the movements from beginning until the shipment is completed. In this segment, in the directive to answer the formulation of concept and movement planning of container delivery, the elaborations are based on the case studies of company 1, company 8, company 9, company 11 and company 12. Findings on Fleets Movement Management Framework in Relation to Formulation of Concept and Movement Planning in DTM are summarized in Exhibit 1.

Exhibit 1: Findings on Fleets Movement Management Framework in Relation toFormulation Concept of DTM and Movement Planning.

Issues Addressed: The Formulation Concept of DTM and Movement Planning in Haulage Industry.

How does the present formulation Concept of DTM and movement Planning applicable in Fleets Management Framework?

Respondent 1: Senior Executive Company 8

- $\quad$ Doing right formulation in movement planning will enable hauliers to deliver the containers to customers accordingly.

- The most important part is the information's given by customers must be precise otherwise hauliers will facing problems in making an efficient delivery.

- $\quad$ Failed to adhere the requirements by hauliers it will affect the resources utilization, especially

- $\quad$ The hauliers have many movements to be delivered and picked up using same trailers. Respondent 2: Operation Coordinator Company 9

- The movement planning and concepts start with determining the number of containers movement required by customers and followed by the number of resources that are required such as drivers, prime movers and trailers.

- $\quad$ The haulage operators adopt their movement delivery whereby uncoupled trailers with containers mounted will be left out at the customer's premises for stuffing and un-stuffing.

- This will take a day and more prior readiness for collection. It is common case for the container to be used as a temporary storage area by customers.

- $\quad$ The trailers were also used by ports operators for the pre-mounting activities.

- $\quad$ The availability of trailers for haulage operation is acknowledged very significant.

Respondent 3: Supply Chain Manager Company 1

- The formulation of concept in using the lesser number of trailers during movement planning it will reduce the unnecessary costs for the trailers.

- $\quad$ Having precise drop trailer monitoring the turnaround trailers can be improved and this will enable hauliers to deliver more container movement and optimizing on trailers utilization.

- $\quad$ The concept of drop trailer movement planning has been used since very beginning and it was followed by all players until today.

- In certain extend the drop trailer movement concept could be benefited to the operators as they don't need to wait for every single trailer readiness to be trucked out for the next assignment.

Respondent 4: Head of Branch Company 11

- $\quad$ The concept of drop trailer movement planning has been used since very beginning and it was followed by all players until today.

- In certain extend, the drop trailer movement concept could be benefited to the operators as they do not need to wait for every single trailer readiness to be trucked out for the next deliveries.

Respondent 5: Operation Manager Company 12

- In order to improve productivity, an effective formulation, the planning is important

- $\quad$ Since hauliers have high demand for delivery they must make sure drivers, prime movers and trailers are sufficient to complete the shipments

5.2. Movement Planning in DTM 
The DTM planning begins with the total volume of containers or shipments that requested by customers and to be delivered or collected. The DTM planning process starts by determining the availability of drivers, prime movers and trailers for deliveries. The deliberation in DTM planning stages are based on respondents as referred to Company 5, Company 7, Company 10 and Company 11. DTM planning is used to find optimal deliveries between two or more at given location. The elements of the tasks are based on different criteria for example the number of containers that are required for that particular movement, number of drivers, prime movers and trailers need to be tasked for the movement deliveries including the date and time that the containers are required by the customers. The empty or laden containers are to be picked up and delivered until end destinations. It involves whether for exports containers to seaport or return empty or return to container depot for the import shipments. The timing in DTM at customers' premises are to be measured.

Findings on Fleets Movement Management Framework in Relation to DTM are summarized in Exhibit 2.

Exhibit 2: Findings on Fleets Movement Management Framework in Relation to Journey Planning concept of DTM

Issues Addressed: Drop Trailer Method (DTM) and Journey Planning in Haulage Industry.

How does the drop trailer journey planning execute in Fleets Movement Management Framework?

Respondent 1: Head of Operation Company 5.

- $\quad$ The availability of drivers, prime movers and trailers are vital for preparing DTM planning.

- Upon receiving the customers' requests the hauliers will do the DTM planning and based on customer requirements.

- $\quad$ Hauliers will plan the DTM planning for the next day operations.

- $\quad$ The prime movers and trailers will be the main equipment for deliveries

- $\quad$ Daily delivery is targeted and met for the better fleet's turnaround.

- The drivers need to haul back the trailers as to send another order or request. Respondent 2: Operation Manager Company 7

- $\quad$ Upon receiving request from customers, the driver assignment shall be made

- $\quad$ Operations Department then allocates the prime mover and trailer accordingly.

- $\quad$ Categorize with urgent or non-urgent on containers requirement, place of delivery and the arrival of vessel will be taking into consideration in planning the DTM planning.

- $\quad$ Two-ways monitoring and communication of DTM i.e between hauliers and customers

- $\quad$ Communication with customers and port operators, inform the hauliers on the delays

Respondent 3: Branch Manager Company 10

- Without appropriate planning in DTM, it is impossible for smooth deliveries.

- $\quad$ The scheduling for the drivers, prime movers and trailers should include the journey planning.

- $\quad$ The targeted movement is 5 or 7 local trip per prime movers and required 5 to 7 trailers respectively per-day (in 8 hours working)

- Hauliers need to ensure that their equipment utilized and able to cover the operating costs and targeted profit.

- $\quad$ The cut off time of RFD (request for delivery) is at $5 \mathrm{pm}$ on daily basis, any order beyond that timeline we will process on the next day.

- $\quad$ Containers movement request normally will be received via e-mail and haulage systems or selfsubmission or through forwarding agents.

- $\quad$ The request will be processed and printed copy of request forwarded to operations department for planning.

- Journey planning usually be based on the total numbers of request by customers.

- Journey planning will be executed based on customers and locations.

- Journey planning should combine few orders or multi tasks within the operational hours for costs saving and better fleet utilization.

- Good communication with customers, drivers and operations staff could reduce the waste of resources and times.

- $\quad$ Better journey planning shall improve the trailers turn-around and revenue.

Respondent 4: Head of Branch Company 11

- Journey planning is formulated should considering on delivery areas such as local and outstation movements.

- $\quad$ Local delivery is within 90kms radius whilst for outstation is exceeding $90 \mathrm{kms}$ from the base.

- $\quad$ Determine the number of RFD and information, shipment status (import or export) 
- $\quad$ Locations, total numbers of drivers, prime movers and trailers are required.

- $\quad$ Targeted trips each driver- 7 trips per for local and 1 to 2 outstation trips (8 hours working day)

- $\quad$ Each prime mover can deliver high number of trailers' turnaround depend to the loading and unloading at customers' premises.

- $\quad$ Using the container handling equipment for effective works.

- Type and sizes of container should suitable with trailers.

- $\quad$ Better ratio between prime mover and trailers for better turnaround of machineries

\subsection{Movement Delivery}

Movement deliveries for the entire haulage operators are using three flow methods such as journey order, handed over to the driver and movement delivery. In the case of export container, driver will attach the prime mover with the empty trailer and moving to the respective depot or container yards and picking up the empty container which was allocated by the shipping line. While for import delivery, upon receiving the journey order from operations department, driver will start moving to the respective port terminal to pick up the laden import container which has already mounted on the trailer. The trailer that utilized is from laden export container that left at the port terminal or else the driver will be transported the empty trailer and straight away pick up the laden import container at port indicated terminal. The findings of movement delivery phase based on respondents Company 1, Company 2, Company 4 and Company 6 are summarized in Exhibit 3.

Exhibit 3: Findings on Fleets Movement Management Framework on DTM in Relation to Movement Delivery. Issues Addressed: Movement Delivery in Haulage Industry.

When and how the delivery are commencing?

Respondent 1: Manager Supply Chain- Company 1

- $\quad$ The journey order, attached, documents, container release order, customs, forms endorsed by shipping lines and forwarding agent. Stated the place of container yards for the empty container to be collected and the details of import containers.

- Upon the empty container lifted on trailer, the driver will write down the container number on the journey order form and RFD and straight away deliver the container.

- Once customers received the container and delivery order or RFD is endorsed and the driver will detach the trailer at customer premise for loading or unloading activity.

Respondent 2: Operation Manager - Company 2

- Upon journey order was passed to the driver and then will proceed to search for empty trailer available or laden container for the delivery.

- $\quad$ After the container mounted at container yard or port terminal, driver will deliver the container to the mentioned customers and left it at loading or unloading bays.

- $\quad$ Pre-advise and notification on every movement delivery to customer is necessary, enable the customer to make early preparation for loading and unloading of goods.

Respondent 3: Head of Operation- Company 4

- $\quad$ Movement delivery is the main business activities.

- $\quad$ Effective planning and optimizing the resources will generate for better revenues

Respondent 4: Senior Customer Service- Company 6

- $\quad$ Availability of trailers is important, insufficient will jeopardize on the planning.

- The shortage of trailers caused by the customers' delays due to loading and unloading

- $\quad$ Trailers detention will effect on the hauliers' planning

\subsection{Movement Monitoring and Collection}

The monitoring in container collection for exports begin from the date and time of the trailer left at customer places until the information on readiness received. Hauliers to determine the time range of the detained trailers by customer. A specific time for loading and unloading given as agreed in the agreement. If more than stipulated times, the detention chargers shall be imposed as per T \& C (Terms and conditions). Continue the journey order and the driver to pick up the ready laden container at customers' premises and sending the container to the respective seaport. The same prime mover is assigned to couple the laden container at seaport and send to the customers (import container). Import container shall be monitored from the date of laden container on trailer and left out at customer' place for loading and unloading. Upon the information's on readiness to collect the empty container is received, the number of days delayed will be determined as the detention charges. Laden container 
for export will be picking up and send to the seaport and the empty import container at customers' premises will send to the container yards for maintenance and rescheduling purposes. The findings of DTM monitoring and collection stage from the respondents; Company 1, Company 7 and Company 11 are summarized in Exhibit 4.

Exhibit 4: Findings on Fleets Movement Management Framework in Relation to DTM Monitoring and Collection.

Issues Addressed: Monitoring the movement in Haulage Industry.

How and when the monitoring of movement and collection are performed?

Respondent 1: Manager Supply Chain - Company 1

- $\quad$ For monitoring and collection purposes, once container arrived at customer's place the driver will obtain the consignment note $(\mathrm{CN})$ and was endorsed by customer with the date and time of consignment received.

- $\quad$ Driver then will pass the $\mathrm{CN}$ copy to operations office- customer service department and start monitoring the movement and readiness.

- The priority for container delivery and collection either for export or import is based on return of prime mover and empty trailer.

- $\quad$ The idling trailer which parked at customer premises within 3 hours to avoid further effect on other delivery.

Respondent 2: Operation Manager - Company 7

- $\quad$ Customer needs to understand on the "Terms and Conditions of Services" especially on detention charges.

- $\quad$ Operation staff will keep on monitoring the trailer from arrival time at customers' place.

- Communication with customer is important and brief on the shipment status.

- $\quad$ Monitoring is not an easy task so they have to monitor every single trailer.

Respondent 3: Head of Branch - Company 11

- Closely monitor the movement of trailers' utilization due to the following reasons;

Improving productivity of movements

Monitoring allows the manager to effectively manage their trailers, minimize idling times and enhance productivity.

\section{Accurate Journey Planning}

Monitoring on the movement is able to establish a real-time delivery, collection and better reporting on exact location of trailers. The report is used to plan for future movement delivery, maximize to usage of trailers and improve revenues.

\section{Lowers operating costs}

Trailers' idling at customer's premises will incur costs and monitoring will be benefited to the haulilers.

\section{Helps secure the trailers}

It helps to prevent theft and pilferages on trailers which left at customer's premises.

\section{Optimize trailer utilization}

Monitoring is able to improve the trailers performance and down times. It also able to provide the customers with accurate billing information and trailers' detention charges.

\section{Improve communication}

Close communication and monitoring on container arrivals and collection times will improve the relationship

\section{Conclusion}

This research had proposed a framework for drop trailer method (TDM) in haulage industry and it based on suggestions from respondents during survey and case studies. The inputs were analyzed and transform as the final structure of framework. Haulage operators should be focusing on the implementation and formulation of the DTM. At the same times it also benefited to other related movements such as journey planning, movement delivery, haulage monitoring, laden and empty collections as well as optimizing on trailers' deployment. It is timely that the DTM management framework is necessary and acted as a parameter for haulage operators in managing the trailers' utilization. This overview and general evaluation are to find the gaps between the academic literatures and practitioners. The findings had contributed in the direction of the fleets management theory and framework which also added for a new context in managing the DTM planning. This study has a magnitude on the knowledge of DTM issues by providing the empirical evidences on monitoring aspects and discovers on the gaps as practiced. It also involved in monitoring on drivers prime movers and containers but the most importantly is the DTM approaches. The findings of this study are able to describe the context on 
successful monitoring and implementation in trailers management for the hauliers. This study is able to serve as a guideline for the haulage organization that involve in monitoring trailers for the best and systematic ways towards the DTM.

\section{References}

1. Azizi, A. S., Hassan, M. G., Akanmu, M. D., \& Melan, M. (2019). Relationship between logistical support factors and effective contract management in royal malaysian navy. International Journal of Supply Chain Management, 8(3), 1010-1017.

2. Azlan M et al., 2014; Logistics performance measurements-issues and reviews/ The 6th International Conference On Logistics and Transport 2014 (CILT); ISSN 2392-57282014

3. Baxter \& Jack, (2008): Qualitative Case Study Methodology: Study Design and Implementation for Novice Researchers. The Qualitative Report Volume 13 Number 4 http://www.nova.edu/ssss/QR/QR13-4/baxter.pdf

4. Berg, (2001): Duration models: specification, identification and multiple durations. Handbook of Econometrics, Edition 1, volume 5, chapter 55, pages 3381-3460, Elsevier.

5. Bowersox, Closs\& Cooper., (2002): Supply Chain - Logistics Management;Business \& Economics; McGraw-Hill, 11 Jan 2002

6. Creswell (2013): Achieving integration in mixed methods designs-principles and Practices.Educational Psychology, University of Nebraska-Lincoln, College.

7. Christopher, M. (2011): "Supply Chain 2.0": managing supply chains in the era of turbulence.International Journal of Physical Distribution \& Logistics Management, 41 (1), 63-82

8. David J. et al., 2016; Drivers of food waste and their implications for sustainable policy, Development Stony Brook, United States, Department of Technology and Society

9. Fabricio, (2004); Risk and agri-food supply chain performance: perceptions from initial analysis; https://pdfs.semanticscholar.org/e27b/436dd7d48f72d18879a0e626f56f96b87fea.pdf

10. Forslund, 2007; The impact of performance management on customers' expected logistics Performance.International Journal of Operations Production,Management, Emerald.com

11. Jalil, N. A., Prapinit, P., Melan, M., \&Mustaffa, A. B. (2019). Adoption of business intelligence technological, individual and supply chain efficiency. Paper presented at the Proceedings - 2019 International Conference on Machine Learning, Big Data and Business Intelligence, MLBDBI 2019, 67-73. doi:10.1109/MLBDBI48998.2019.00021

12. Halizahari, M., \&Mustakim, M. (2016). Initiatives to prolong aging assets life cycle: A case study in royal malaysian navy. International Journal of Supply Chain Management, 5(2), 122-126.

13. Johnson M. (2008): Supply chain management for servitudes products. International Journal of Production Economics, Volume 114, Issue 1, July 2008, Pages 27-39 Canfield School of Management

14. Lovelock and Gummesson, (2004): Whither Services Marketing? Journal of Service Research, 7 (1), 20-41 DOI: 10.1177/1094670504266131

15. Malaysian Haulage Association, (2014): Annual Report and News / RURB-Logistics-Draft-FullReport.pdf http://www.mpc.gov.my/wp-content/uploads/2016/04/

16. Maria Emilson\& Hanna Johansson (2011), Empty Trailer and empty Kilometers, Department of Industrial Management and Logistics Lund University

17. Mauro Vivaldini, Silvio R I Pires (2012): Improving logistics services through the technology used in fleet management; https://www.researchgate.net/publication/DOI: 10.4301/S1807-17752012000300006

18. Melan, M., Zahid, M, M., Sabar, R. (2019) Effectiveness on Drop Trailer Method (DTM) of Haulage Industry in Malaysia International Journal of Supply Chain Management Vol 8, No 5.

19. Mentzer, J.T. and Konrad, B.P. (1991) An Efficiency/Effectiveness Approach to Logistics Performance Analysis. Journal of Business Logistics, 12, 33-62

20. Miller (1990): A framework for integrating activity-based costing and the balanced scorecard into the logistics strategy development and monitoring process.

21. Road Transport Act (1987) [Act 333] Provision about the regulation of motor vehicles Ministry of Transport, Malaysia

22. Omotayo, A., \& Melan, M. (2017). Factors influencing the information and communication technology (ICT) of third party logistics in Malaysia. International Journal of Supply Chain Management, 6(2), 202-208.

23. Oyster Bay, NY: ABI Research, (2005): How to Maximize Trailer Utilization and Reduce Dormancy https://www.xtralease.com/SiteCollectionDocuments

24. Parwani K \& Jagadeesh R, (2012): Reduction of Turnaround Time for Outbound Logistics (Finished Goods only) in a Food Processing Industry/https://www.semanticscholar.org/ 
25. Peter MbuthiaGitahi, Dr Kennedy Ogollah, (2014): Influence of fleet management practices on service delivery to refugees in United Nations high commissioner for refugees kenya programme. European Journal of Business Management. 2014;2(1):336-341.

26. Prapinit,P., Sabar, R., Melan, M. (2019) Demand for Logistics Management Studies in North Eastern Thailand International Journal of Supply Chain Management, Vol 8, No 5.

27. Tengku Jamaluddin Bin Tengku Mahmud Shah Al-haj (2003) Liberalization of the container haulage industry in Malaysia. Transport and Communications Bulletin for Asia and the Pacific No. 73, 2003

28. VojkoPotocan, (2006): Interdependence of systems theories-potential innovation supporting innovation; https://www.emerald.com/

30. ZailaniMohd Zaid and Muhammad Zaly Shah (2007). Performance Measurement in Malaysian Container Haulage Industry: A Critical Evaluation. FakultiAlam Bina Postgraduate Seminar, UTM, Skudai, Malaysia 